\title{
A Look from the Inside: MicroCT Analysis of Burned Bones
}

\author{
Francesco Boschin ${ }^{1^{*}}$, Clément Zanolli ${ }^{2}$, Federico Bernardini ${ }^{2,3}$, Francesco Princivalle ${ }^{4}$, and Claudio Tuniz ${ }^{2,3}$
}

Author Addresses: ${ }^{1}$ Dipartimento di Scienze Fisiche, della Terra e dell'Ambiente, UR Preistoria e Antropologia, Università degli Studi di Siena, Italy. ${ }^{2}$ Multidisciplinary Laboratory, The Abdus Salam International Centre for Theoretical Physics, Italy. ${ }^{3}$ Centro Fermi, Museo Storico della Fisica, Centro di Studi e Ricerche Enrico Fermi, Italy. ${ }^{4}$ Università degli Studi di Trieste, Dipartimento di Matematica e Geoscienze, Italy.

*Corresponding Author: fboschin@hotmail.com

Received: March 5, 2015

Volume: 6(2):258-266

Published: December 18, 2015

(C) 2015 Society of Ethnobiology

Abstract: MicroCT imaging is increasingly used in paleoanthropological and zooarchaeological research to analyse the internal microstructure of bone, replacing comparatively invasive and destructive methods. Consequently the analytical potential of this relatively new 3D imaging technology can be enhanced by developing discipline specific protocols for archaeological analysis. Here we examine how the microstructure of mammal bone changes after burning and explore if $X$ ray computed microtomography (microCT) can be used to obtain reliable information from burned specimens. We subjected domestic pig, roe deer, and red fox bones to burning at different temperatures and for different periods using an oven and an open fire. We observed significant changes in the three-dimensional microstructure of trabecular bone, suggesting that biomechanical studies or other analyses (for instance, determination of age-at-death) can be compromised by burning. In addition, bone subjected to very high temperatures $\left(600^{\circ} \mathrm{C}\right.$ or more) became cracked, posing challenges for quantifying characteristics of bone microstructure. Specimens burned at $600^{\circ} \mathrm{C}$ or greater temperatures, exhibit a characteristic crisscross cracking pattern concentrated in the cortical region of the epiphyses. This feature, which can be readily observed on the surface of whole bone, could help the identification of heavily burned specimens that are small fragments, where color and surface texture are altered by diagenesis or weathering.

Keywords: MicroCT imaging, Burned bones, Taphonomy, Zooarchaeology

\section{Introduction}

High resolution X-ray imaging is increasingly used in zooarchaeological research to better understand taphonomic processes that bones undergo during butchery and deposition in the archaeological record (Bello et al. 2013; Boschin et al. 2015; Bradfield 2013; Shackleford et al. 2013; Tuniz et al. 2012). This approach is relatively new in archaeology and offers the opportunity to develop and improve analytical protocols for zooarchaeological research into bone microstructure. Since the physical properties of mammal bone are related to age and adaptation to mechanical loads, characteristics of bone microstructure can be indicative of age-at-death and life history conditions (Agarwal et al. 2004; Barak et al. 2011; Boschin et al. 2015; Brickley et al. 1999; Macho et al. 2005; Tanck et al. 2001; Shackleford et al. 2013). For instance, bone microstructure has the potential to yield inferences about domestic stock management or to differentiate domestic individuals from their wild ancestors (Boschin et al. 2015; Shackleford et al. 2013).
X-ray computed microtomography (microCT) scanning can also be used to evaluate changes in mammal bone microstructure from burned specimens, which is the focus of this study. Burned bones and burned bone fragments can be abundant in archaeological sites and their presence can provide insight into preservation conditions and processing decisions (Riedel and Tecchiati 2005). The analysis of burned bones in archaeological samples can shed light on hominid evolution, and culinary as well as ritual traditions (Berna et al. 2012; Cain 2005; Clark and Ligouis 2010; McCutcheon 1992; Steffen and Mackie 2005; Stiner et al. 1995). The effect of burning on bone shrinkage, crystallization, color, and surface alterations has been previously observed on modern and archaeological samples heated in ovens and campfires (Bonucci and Graziani 1975; Nicholson 1993; Shipman et al. 1984; Stiner et al. 1995). Histological analyses of burned bones have been carried out by Hanson and Cain (2007), but to our knowledge, a thorough three-dimensional (3D), 
Table 1. Bone measurements (mm) after von den Driesch (1976).

\begin{tabular}{|c|c|c|c|c|c|c|c|}
\hline Specimen ID & Taxon & Element & Combustion & GL/GLI/GLpe & $\mathrm{Bp}$ & $\mathrm{Bd}$ & Measure $2^{*}$ \\
\hline \multirow{3}{*}{1} & \multirow{3}{*}{ Vulpes vulpes } & \multirow{3}{*}{ Talus } & Not burned & 18.7 & - & - & 8.1 \\
\hline & & & Oven $-400^{\circ} \mathrm{C}$ & 18.5 & - & - & 7.1 \\
\hline & & & Oven $-600^{\circ} \mathrm{C}$ & 18.5 & - & - & 7.1 \\
\hline \multirow{3}{*}{2} & \multirow{3}{*}{ Vulpes vulpes } & \multirow{3}{*}{ Talus } & Not burned & 19.5 & - & - & 7.8 \\
\hline & & & Oven $-400^{\circ} \mathrm{C}$ & 19.5 & - & - & 7.3 \\
\hline & & & Oven $-600^{\circ} \mathrm{C}$ & 19.5 & - & - & 7.0 \\
\hline \multirow{3}{*}{3} & \multirow{3}{*}{ Sus domesticus } & \multirow{3}{*}{ Talus } & Not burned & 59.7 & - & 39.0 & - \\
\hline & & & Oven $-400^{\circ} \mathrm{C}$ & 59.7 & - & 37.4 & - \\
\hline & & & Oven $-600^{\circ} \mathrm{C}$ & 59.0 & - & 37.1 & - \\
\hline \multirow{2}{*}{4} & \multirow{2}{*}{ Capreolus capreolus } & \multirow{2}{*}{ Phalanx 1} & Not burned & 35.5 & 11.8 & 9.7 & - \\
\hline & & & Open fire $-900^{\circ} \mathrm{C}$ & 31.6 & 9.7 & 7.4 & - \\
\hline \multirow{2}{*}{5} & \multirow{2}{*}{ Capreolus capreolus } & \multirow{2}{*}{ Phalanx 1} & Not burned & 38.5 & 12.0 & - & - \\
\hline & & & Open fire $-900^{\circ} \mathrm{C}$ & - & 8.8 & - & - \\
\hline
\end{tabular}

*Width of the trochlea at the apex of each condyle.

quantitative imaging study on the internal structural changes in bone induced by burning has not been performed. A preliminary Magnetic Resonance Imaging (MRI) analysis was carried out by Thompson and Chudek (2007) on a defleshed long bone of domestic sheep that had been exposed to different heating conditions. As the authors concluded, more in -depth studies are required to improve the contribution of this type of research to forensic anthropology and archaeology.

The primary aim of the work presented here is to understand if burned bones can be studied by microCT analyses to collect reliable data on microstructure. In addition, we aim to analyze internal features of bone to more reliably identify burned specimens.

\section{Materials and Methods}

We conducted burning experiments using two red fox talii (Vulpes vulpes Linnaeus Canidae), one domestic pig talus (Sus domesticus Erxleben Suidae) and two first phalanges of roe deer (Capreolus capreolus Linnaeus Cervidae), at different temperatures in an oven and in an open fire (Table 1). All bones were defleshed before burning. Talus bones from each species were chosen as representative of 'spongy' bones, and phalanges were selected to understand heat-induced bone modifications in the diaphysis (shaft portion) of long bones. Roe deer bones were collected in the field, and the pig specimen was analyzed a few days after butchering. The choice of these specimens was influenced by their availability. The fox bones (specimens 1 and 2) were analyzed in a previous study (Boschin et al. 2015) and are part of the osteological reference collection of the University of Siena (specimens 160 and 149, respectively). The red fox and roe deer specimens came from adult individuals, while the domestic pig talus came from a subadult (about 1 year old). Fox bones appeared to have already lost their fat content, whilst roe deer and domestic pig specimens were still greasy before the burning experiments.

The red fox and domestic pig bones were heated twice in an oven at the University of Trieste (Italy): the first time at $400^{\circ} \mathrm{C}$ and the second time at $600^{\circ} \mathrm{C}$. The temperature was maintained for one hour and then the specimens were removed. The two roe deer phalanges were burned in an open fire over a clay-rich sediment. The open fire used about $5 \mathrm{~kg}$ of Prunus domestica Linnaeus Rosaceae and Vitis vinifera Linnaeus Vitaceae wood. Hardwood pieces were of small diameter (less than $10 \mathrm{~cm}$ ). The peak temperature of 

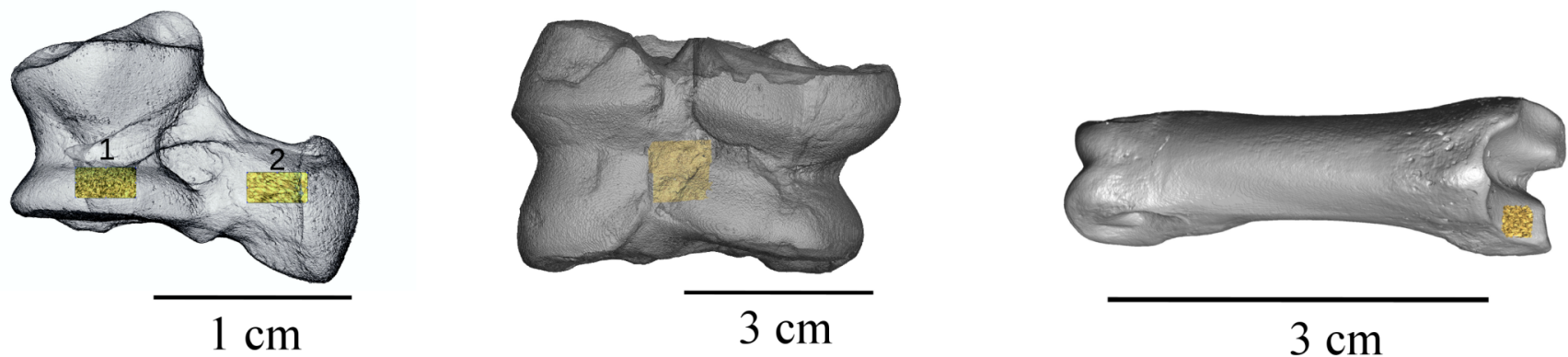

Figure 1. 3D renderings of bone elements subjected to Micro CT analysis. Hatched rectangles on the bone surfaces indicate the position of the subvolumes sampled and described in the text. Represented bones are: specimen 1 - red fox talus (on the left); specimen 3 - pig talus (in the middle); specimen 4 - roe deer first phalanx (on the right).

about $900^{\circ} \mathrm{C}$, measured with a thermocouple, was reached within a few minutes, similar to that as observed by other authors (Stiner et al. 1995). This open fire was allowed to burn down naturally, and the coals were then allowed to smoulder through the night. Burned bones were collected the following morning.

Each specimen was measured to the nearest 0.1 $\mathrm{mm}$ prior to and after burning (Table 1), following von den Driesch (1976) with the exception of the measure of the width of the trochlea at the apex of each condyle for the red fox talii. To evaluate internal micro-structural modifications, microCT scans were carried out at the Abdus Salam International Centre for Theoretical Physics of Trieste (ICTP) (Tuniz et al. 2013) on each bone using the following parameters: voltage $110 \mathrm{kV}$; current $90 \mu \mathrm{A}$; 2400 projections. The virtual record of the specimens was reconstructed with an isometric voxel size ranging from 17.41 to $30.95 \mu \mathrm{m}$. MicroCT imaging analyses were performed before and after heating sessions using a semiautomatic threshold-based image segmentation (Coleman and Colbert 2007) to separate bone tissue from the interstitial air entrapped between the trabeculae. Rectangular cubes (hereafter termed 'subvolumes') of trabecular bone were extracted from all specimens to evaluate the structural changes that occurred to each bone after burning (Figure 1). Subvolume (or Volume of interest, VOI) extraction is a virtual biopsy technique currently used in MicroCT bone analysis (Lazenby et al. 2011). Characteristics of the cancellous bone were analysed using the imaging software BoneJ (Doube et al. 2010). The following parameters were calculated for each subvolume: the connectivity (number of trabeculae); the degree of anisotropy (directional stretching); a structural model index (Hildebrand and Rüegsegger 1997); the mean trabecular thickness in $\mu \mathrm{m}$; the mean trabecular spacing in $\mu \mathrm{m}$; the bone volume/total volume ratio (BV/TV), and the fraction of concave surface. These various parameters offer a variety of quantitative measures of the degree to which microstructural characteristics of bone changed when subjected to burning. Since burned specimens were also affected by shrinkage, an additional subvolume was extracted

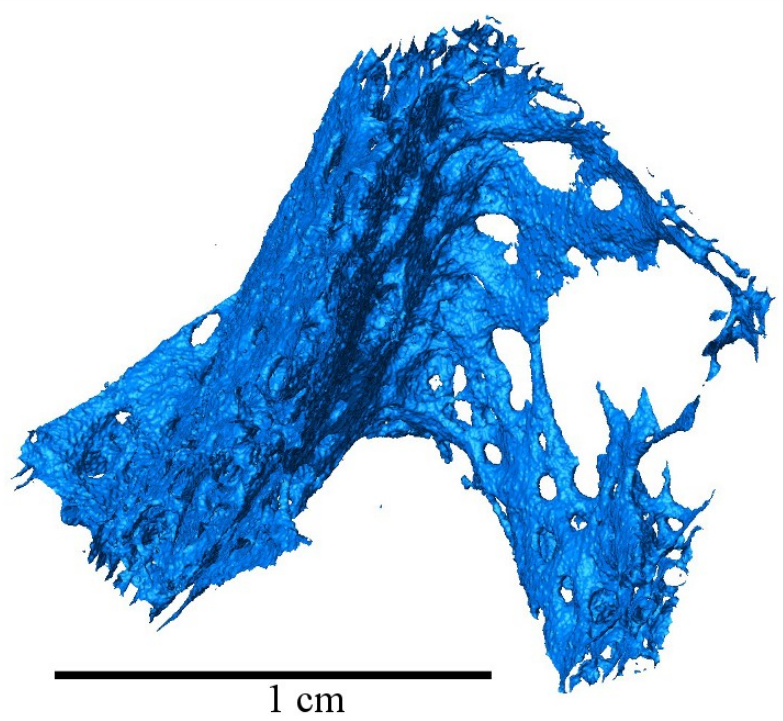

Figure 2. Subvolume extracted from the domestic pig talus showing the trabecular network. The large void in upper right of this image does not allow for a conventional measurement of mean trabecular spacing. Nevertheless, this part of bone was chosen for the high reproducibility across measurement angles. 
Table 2. Bone Volume/Total Volume (BV/TV) counted for the whole bones before and after the heating sessions. \% of change of the parameter was calculated following the formula $=$ (initial value/final value*100)-100.

\begin{tabular}{|c|c|c|c|c|c|}
\hline Specimen ID & Taxon & Element & Combustion & $\mathrm{BV} / \mathrm{TV}$ & $\%$ of change \\
\hline \multirow{3}{*}{1} & \multirow{3}{*}{ Vulpes vulpes } & \multirow{3}{*}{ Talus } & Not burned & 0.66 & - \\
\hline & & & Oven $-400^{\circ} \mathrm{C}$ & 0.69 & 4.54 \\
\hline & & & Oven $-600^{\circ} \mathrm{C}$ & 0.74 & 12.00 \\
\hline \multirow{3}{*}{2} & \multirow{3}{*}{ Vulpes vulpes } & \multirow{3}{*}{ Talus } & Not burned & 0.71 & - \\
\hline & & & Oven $-400^{\circ} \mathrm{C}$ & 0.65 & -8.45 \\
\hline & & & Oven $-600^{\circ} \mathrm{C}$ & 0.71 & 0 \\
\hline \multirow{2}{*}{4} & \multirow{2}{*}{$\begin{array}{l}\text { Capreolus } \\
\text { capreolus }\end{array}$} & \multirow{2}{*}{ Phalanx 1} & Not burned & 53.23 & - \\
\hline & & & Open fire $-900^{\circ} \mathrm{C}$ & 48.28 & -7.50 \\
\hline
\end{tabular}

from every bone prior to burning in order to provide a reference scale for comparison after burning (Lazenby et al. 2011). Mean trabecular spacing could not be quantified from the domestic pig talus, due to the peculiar shape of that portion of trabecular network (Figure 2).

Micro CT analysis of the diaphyses of the roe deer phalanges were distinguished from the proximal and distal epiphyses, and the following parameters were measured: bone volume; volume of the voids within the diaphysis; and volume of the marrow cavity. MicroCT scans were carried out the day after burning. In the case of the pig and the red fox talii, a few days passed between heating sessions. Specimens are numbered from 1 to 5 in Table 1 .

\section{Results}

All burned bones exhibited shrinkage in their absolute volume, though this was variable between species and with temperature (Table 1). These results are consistent with previous observations (e.g., Shipman et al. 1984) in which the degree of bone shrinkage was positively related to higher temperatures. The greatest shrinkage was observed for the roe deer phalanges (Greatest Length of the peripheral half - GLpe - from 35.5 to 31.6 in Specimen 4; Greatest Breadth of the proximal end - Bp - from 11.8 to 9.7 and from 12.0 to 8.8). In addition, heat-induced shrinkage caused Specimen 5 to fracture along the shaft, making it impossible to measure the bone's length (GLpe). Specimen 4 does not show any macroscopic characteristics indicating marked shrinkage.

The ratio of bone volume to total volume (BV/ TV) increases after burning in Specimen 1 but decreases in Specimen 4 and follows an ambiguous pattern in Specimen 2. The BV/TV ratio was not recorded for Specimens 3 and 5 due to the presence of visible cracks that compromised the analysis. (Table 2).

Characteristics of bone microstructure show drastic changes after burning (Tables 3 and 4). Most of the measurable changes were in trabecular shape (from plate-like trabeculae to rod-like trabeculae or vice versa as indicated by the Structure Model index), thickness, and spacing. Changes in the BV/TV ratio and anisotropy do not appear to be significant in some of extracted subvolumes (Tables 3 and 4). The decrease of bone volume of the diaphysis of Specimen 4 from 53.64 to $43.69 \%$ of the total volume is mirrored by an increase in the marrow cavity volume from 46.14 to $56.23 \%$. Likewise, the volume of voids within the compact bone of the diaphysis also decreases from 0.23 to $0.08 \%$ (numbers not in Tables).

At $600^{\circ} \mathrm{C}$ the cortical bone of all epiphyses in the study exhibits small, thin cracks that are sometimes criss-crossed (Figure 3). A polyhedral patterning (pentagonal or hexagonal) is sometimes visible. Virtual transversal cross-sections of Specimen 4 show that greyscale values of the external part of compact bone of the diaphyseal shaft are higher than those of the internal part (220 vs. 137), thus indicating a higher density (Figure 3B). This feature was not observed in Specimen 5, which fractured after heating-induced deformation whereby both inner and outer shaft surfaces then burned with the same intensity. Most of cracks of the diaphysis of Specimen 4 appear to be perpendicular to the outer surface and do not reach 
Table 3. Parameters measured on the subvolumes of trabecular tissue. Abbreviations: DA: degree of anisotropy; C: connectivity; SMI: Skeletal Model Index; Tb.Th: mean of Trabecular Thickness; Tb.Sp.: mean of trabecular spacing; BV/TV: Bone Volume/Total Volume; FCS: Fraction of Concave Surface.

\begin{tabular}{|c|c|c|c|c|c|c|c|c|c|c|}
\hline $\begin{array}{l}\text { Specimen } \\
\text { ID }\end{array}$ & Taxon & Element & Combustion & DA & C & SMI & $\begin{array}{r}\text { Tb. Th. } \\
(\mu \mathrm{m})\end{array}$ & $\begin{array}{l}\text { Tb. Sp. } \\
(\mu \mathrm{m})\end{array}$ & $\mathrm{BV} / \mathrm{TV}$ & FCS (\%) \\
\hline \multirow{6}{*}{1} & \multirow{6}{*}{ Vulpes vulpes } & \multirow{3}{*}{ Talus - vol 1} & Not burned & 0.58 & 137.75 & -0.04 & 233.95 & 380.10 & 0.52 & 0.53 \\
\hline & & & Oven $-400^{\circ} \mathrm{C}$ & 0.62 & 402.88 & 1.29 & 201.78 & 272.99 & 0.50 & 0.37 \\
\hline & & & Oven $-600^{\circ} \mathrm{C}$ & 0.53 & 286.80 & 0.76 & 198.13 & 289.35 & 0.51 & 0.42 \\
\hline & & \multirow{3}{*}{ Talus - vol 2} & Not burned & 0.78 & 449.00 & 0.57 & 229.42 & 340.91 & 0.48 & 0.48 \\
\hline & & & Oven $-400^{\circ} \mathrm{C}$ & 0.79 & 173.00 & 0.85 & 215.54 & 324.87 & 0.48 & 0.45 \\
\hline & & & Oven $-600^{\circ} \mathrm{C}$ & 0.80 & 149.10 & 0.42 & 231.38 & 311.29 & 0.51 & 0.48 \\
\hline \multirow{6}{*}{2} & \multirow{6}{*}{ Vulpes vulpes } & \multirow{3}{*}{ Talus - vol 1} & Not burned & 0.33 & 736.80 & 1.85 & 193.71 & 420.34 & 0.36 & 0.31 \\
\hline & & & Oven $-400^{\circ} \mathrm{C}$ & 0.59 & 289.00 & 1.45 & 173.93 & 367.35 & 0.40 & 0.34 \\
\hline & & & Oven $-600^{\circ} \mathrm{C}$ & 0.59 & 182.00 & 0.44 & 214.84 & 355.86 & 0.48 & 0.47 \\
\hline & & \multirow{3}{*}{ Talus - vol 2} & Not burned & 0.70 & 226.50 & 0.61 & 226.11 & 300.15 & 0.50 & 0.48 \\
\hline & & & Oven $-400^{\circ} \mathrm{C}$ & 0.80 & 184.20 & 1.01 & 205.44 & 354.64 & 0.44 & 0.43 \\
\hline & & & Oven $-600^{\circ} \mathrm{C}$ & 0.80 & 165.30 & 0.30 & 231.20 & 334.97 & 0.50 & 0.50 \\
\hline \multirow{3}{*}{3} & \multirow{3}{*}{ Sus domesticus } & \multirow{3}{*}{ Talus } & Not burned & 0.89 & 748.62 & 0.66 & 330.42 & - & 0.15 & 0.43 \\
\hline & & & Oven $-400^{\circ} \mathrm{C}$ & 0.87 & 989.00 & 2.27 & 257.50 & - & 0.11 & 0.22 \\
\hline & & & Oven $-600^{\circ} \mathrm{C}$ & 0.87 & 830.00 & 1.78 & 277.62 & - & 0.13 & 0.28 \\
\hline \multirow{2}{*}{4} & \multirow{2}{*}{$\begin{array}{l}\text { Capreolus } \\
\text { capreolus }\end{array}$} & \multirow{2}{*}{ Phalanx 1} & Not burned & 0.67 & 135.50 & 3.34 & 181.72 & 463.05 & 0.27 & 0.15 \\
\hline & & & Open fire $-900^{\circ} \mathrm{C}$ & 0.68 & 98.10 & 3.20 & 131.30 & 384.43 & 0.27 & 0.10 \\
\hline \multirow{2}{*}{5} & \multirow{2}{*}{$\begin{array}{l}\text { Capreolus } \\
\text { capreolus }\end{array}$} & \multirow{2}{*}{ Phalanx 1} & Not burned & 0.67 & 184.60 & 1.91 & 168.75 & 306.23 & 0.44 & 0.29 \\
\hline & & & Open fire $-900^{\circ} \mathrm{C}$ & 0.62 & 169.00 & 1.91 & 154.55 & 208.06 & 0.57 & 0.29 \\
\hline
\end{tabular}

the less dense inner layer of bone. Exfoliation is not observed in Specimens 1, 2, 3 and 4. Clear cracks parallel to the outer bone surface are visible only in Specimen 5 and are related to diaphysis breakage and deformation.

\section{Discussion}

This analysis indicates that bone microstructure starts to change significantly at about $400^{\circ} \mathrm{C}$. These results are consistent with other studies reporting burninginduced bone shrinkage at lower temperatures, between 150 and $300^{\circ} \mathrm{C}$ (Shipman et al. 1984). The improvements of this 3D imaging method indicate that the intensity of shrinkage does not occur consistently, but likely varies with shape, bone thickness, and degree of dehydration or other factors.
For instance, Specimen 4 underwent an overall reduction in length by $10.90 \%$, but a reduction in proximal breadth of $17.80 \%$. This anisotropic change affects bone internal structure by deforming the trabecular network and the cortical structure of the bone shaft (diaphysis). Other alterations occurred in the cancellous bone of tarsal elements as well as epiphyses and diaphyseal portions of phalanges. In the cortical portion of tarsal bones the BV/TV ratio appears to change as a result of collapsing (and obstruction) of small porosities observed by an increase in the index value or because of the presence of micro cracks reflected in the diminution of the index value. The degree of dehydration induced by the heating processes appears to be followed by the loss 
Table 4. Percentage change for parameters measured on the subvolumes of trabecular tissue. Formula $=$ (initial value/ final value*100)-100. ${ }^{2}$

\begin{tabular}{|c|c|c|c|c|c|c|c|c|c|c|}
\hline Specimen ID & Taxon & Element & Combustion & DA & C & SMI & $\begin{array}{l}\text { Tb. } \\
\text { Th. }\end{array}$ & $\begin{array}{l}\text { Tb. } \\
\text { Sp. }\end{array}$ & $\mathrm{BV} / \mathrm{TV}$ & FCS \\
\hline \multirow{4}{*}{1} & \multirow{4}{*}{ Vulpes vulpes } & \multirow{2}{*}{ Talus - vol 1} & Oven $-400^{\circ} \mathrm{C}$ & 6.90 & 192.47 & $\begin{array}{r}- \\
3683.33\end{array}$ & 13.75 & 28.18 & -3.85 & -29.79 \\
\hline & & & Oven $-600^{\circ} \mathrm{C}$ & -8.62 & 108.20 & $\begin{array}{r}- \\
2211.11\end{array}$ & 15.31 & $\begin{array}{r}- \\
23.88\end{array}$ & -1.54 & -20.30 \\
\hline & & \multirow{2}{*}{ Talus - vol 2} & Oven $-400^{\circ} \mathrm{C}$ & 1.28 & -61.47 & 49.12 & -6.05 & -4.70 & -1.04 & -6.25 \\
\hline & & & Oven $-600^{\circ} \mathrm{C}$ & 2.56 & -66.79 & -26.49 & 0.85 & -8.69 & 6.25 & 0 \\
\hline \multirow{4}{*}{2} & \multirow{4}{*}{ Vulpes vulpes } & \multirow{2}{*}{ Talus - vol 1} & Oven $-400^{\circ} \mathrm{C}$ & 78.79 & -60.78 & -21.41 & $10.21^{-}$ & 12.61 & 11.11 & 9.68 \\
\hline & & & Oven $-600^{\circ} \mathrm{C}$ & 78.79 & -75.3 & -76.15 & 10.91 & - & 33.33 & 51.61 \\
\hline & & \multirow{2}{*}{ Talus - vol 2} & Oven $-400^{\circ} \mathrm{C}$ & 14.29 & -18.68 & 65.57 & -9.14 & 18.16 & -12.00 & -10.04 \\
\hline & & & Oven $-600^{\circ} \mathrm{C}$ & 14.29 & -27.02 & -50.82 & 2.25 & 11.60 & 0 & 4.60 \\
\hline \multirow{3}{*}{3} & \multirow{3}{*}{ Sus domesticus } & \multirow{3}{*}{ Talus } & Oven $-400^{\circ} \mathrm{C}$ & -2.25 & 32.11 & 244.98 & - & - & -26.67 & -48.8 \\
\hline & & & & & & & & & & \\
\hline & & & Oven $-600^{\circ} \mathrm{C}$ & -2.25 & 10.87 & 170.52 & - & - & -13.33 & -34.88 \\
\hline 4 & Capreolus capreolus & Phalanx 1 & Open fire - & 1.49 & -27.6 & -4.19 & - & - & 0 & -33.33 \\
\hline 5 & Capreolus capreolus & Phalanx 1 & $\begin{array}{l}\text { Open fire - } \\
900^{\circ} \mathrm{C}\end{array}$ & -7.46 & -8.45 & 0 & -8.41 & 32.06 & 29.55 & 0 \\
\hline
\end{tabular}

of pore space in the compact bone of diaphyseal shafts. Changes in BV/TV ratio of cancellous bone can be due to destruction and deformation of trabeculae similarly associated with bone shrinkage. The measure of connectivity may change due to trabecular destruction (corresponding to a diminution of the index), or it may be due to splitting or cracking (corresponding to a possible increase in index values). Diminution in trabecular thickness could also be due to rapid bone dehydration, while diminution in trabecular spacing could be related to shrinkage. An increase in trabecular thickness in three of the red fox specimens examined after the second heating session is difficult to explain with these data.

Criss-crossed cracks of the cortical bone observed in this study (Figure 3) confirm observations made by Hanson and Chain (2007) on burned bone thin sections. They indicate this feature as helpful in identifying high intensity burning, which is associated with white colour matrix (sometimes referred to as calcined bone) and structural disintegration. The higher density of such cracking observed in the outer part of the diaphysis of Specimen 4 (Figure 3B) could be related to the heat-induced recrystallisation of bone.

\section{Conclusions}

In-depth studies of heat-induced changes to bone structure bear significant importance for archaeological and forensic research (Bonucci and Graziani 1975; Cain 2005; Clark and Liguois 2010; Hanson and Cain 2007; Steffen and Mackie 2005; Stiner et al. 1995; Thompson 2004; Thompson and Chudek 2007). Our preliminary data, though based on a small sample, demonstrate that burning affects bone microstructure, and this analysis provides a range of parameters, surpassing the analytical resolution of previous studies. Since some authors have reported differences 


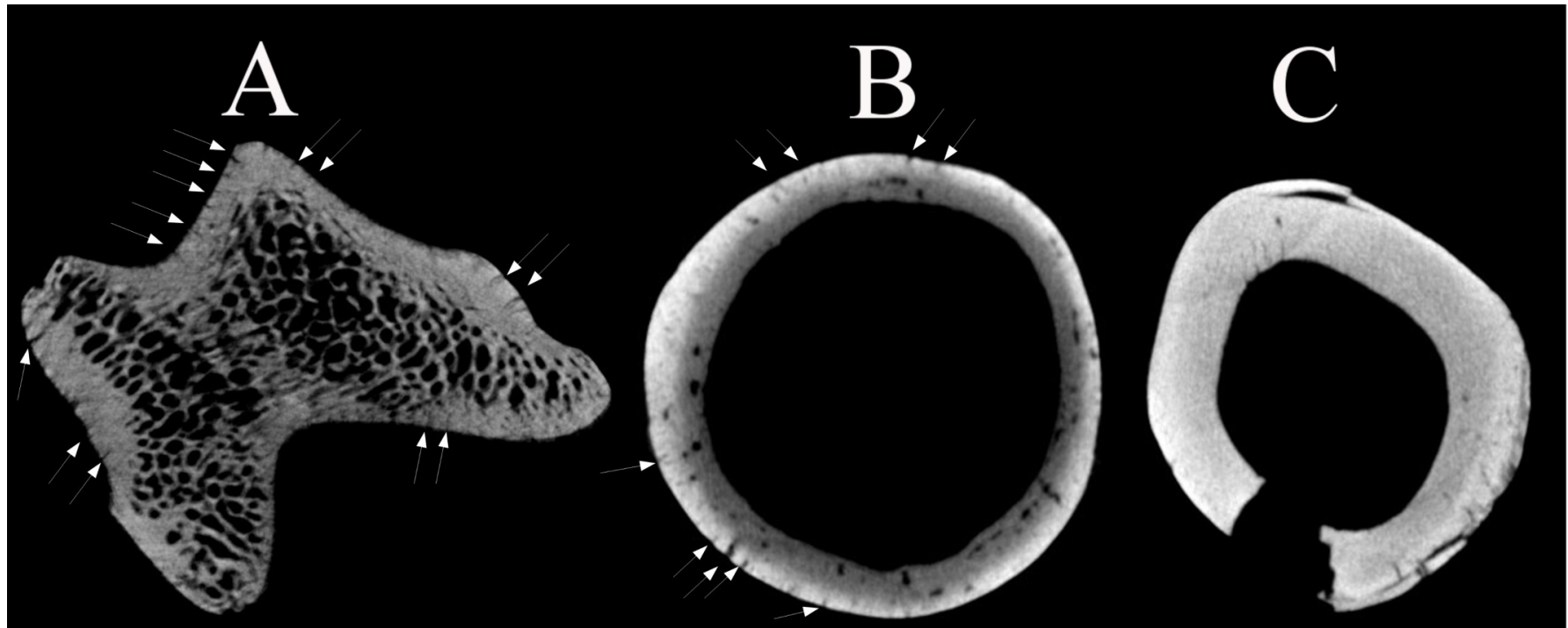

Figure 3. Cross-sections of burned specimens $1(\mathrm{~A})$, burned at $600^{\circ} \mathrm{C}, 4(\mathrm{~B})$, burned at $900^{\circ} \mathrm{C}$, and $5(\mathrm{C})$, burned at $900^{\circ} \mathrm{C}$. Thin cracks perpendicular to the outer surface are visible in the cortical region of specimens $A$ and $B$ (white arrows). Cracks parallel to the outer surface, related to bone deformation, are visible in $\mathrm{C}$. A change in greyscale values from the marrow cavity to the outer surface (indicating an increase in bone density) is visible in $\mathrm{B}$.

between bones burned with the flesh still on and defleshed bones (Binford 1963; Whyte 2001), it has to be pointed out that our study involved only defleshed bones and our observations reflect this condition. We show that bone heating induces a deformation of trabecular shape and strong changes in the trabecular network. We also observe a decrease in trabecular thickness and spacing as well as a change in the number of trabeculae, although these trends are not clear and exceptions have been observed.

This work highlights some important caveats for researchers to consider when working with burned bones. First, since trabecular structure is related to an animal's form of locomotion (Barak et al. 2001), biomechanical studies involving burned bones need to consider how burning may contribute to the observed trabecular structure. Trabecular parameters are also related to age-at-death (Boschin et al. 2015) and heat-induced changes could lead to misinterpretations if the age-at-death is inferred from microscopic observations. The analysis of burned specimens belonging to different age classes would help to clarify if burned specimens can be analysed to obtain at least an approximate age-at-death. In addition, at higher temperatures $\left(600^{\circ} \mathrm{C}\right.$ or more) bone cracks can represent another problem for quantifying characteristics of bone microstructure. Since patterns of cracking can be observed in the whole bone and characterised in three dimensions using micro-CT, further studies are needed to compare heat-induced cracks with those related to diagenesis and weathering. These non-destructive methods can lead to the identification of burned bones whose color and surface preservation were altered by other factors (Hanson and Cain 2007; Nicholson 1993). Finally, to better clarify how heat influences bone microstructure, a next step in our research will be to reproduce these results analysing a larger sample and controlling some parameters (anatomical element and bone conditions before burning) and to examine burned bones that still retain flesh as well as boiled bone, since the influence on 3D bone microstructural organization of such cooking methods that are often identified in archaeological contexts remains unknown.

\section{Acknowledgements}

We are grateful to the editors of this special issue and to the two anonymous reviewers for editing and improving the original manuscript.

\section{Declarations}

Permissions: None declared.

Sources of Funding: This research was supported by the ICTP/Elettra EXACT Project (Elemental X-ray Analysis and Computed Tomography) funded by Autonomous Region Friuli Venezia Giulia (Italy).

Conflicts of Interest: None declared. 


\section{References Cited}

Agarwal, S. C., M. Dimitriu, G. A. Tomlinson, and M. D. Grynpas. 2004. Medieval Trabecular Bone Architecture: The Influence of Age, Sex, and Lifestyle. American Journal of Physical Anthropology 124:33-44. Doi:10.1002/ajpa.10335.

Barak, M. M., D. E. Lieberman and J.-J. Hublin. 2011. A Wolff in Sheep's Clothing: Trabecular Bone Adaptation in Response to Changes in Joint Loading Orientation. Bone 49:1141-1151. Doi:10.1016/j.bone.2011.08.020.

Bello, S. M., I. De Groote, and G. Delbarre. 2013. Application of 3-Dimensional Microscopy and Micro-CT Scanning to the Analysis of Magdalenian Portable Art on Bone and Antler. Journal of Archaeological Science 40:2464-2476. Doi:10.1016/ j.jas.2012.12.016.

Berna, F., P. Goldberg,L. Kolska Horwitz, J. Brink, S. Holt, M. Bamford and M. Chazan. 2012. Microstratigraphic Evidence of In Situ Fire in the Acheulean Strata of Wonderwerk Cave, Northern Cape Province, South Africa. Proceedings of the National Academy of Sciences 109:1215-1220.

Binford, L. R. 1963. An Analysis of Cremations from Three Michigan sites. Wisconsin Archaeologist 44: 98110.

Bonucci, E. and G. Graziani. 1975. Comparative Thermogravimetric, X-ray Diffraction and Electron Microscope Investigations of Burnt Bone from Recent, Ancient and Prehistoric Age. Atti Accademia Nazionale dei Lincei. Classe di Scienze, Fisiche, Matematiche e Naturali Rendiconti LIX:517-532.

Boschin F., F. Bernardini, C. Zanolli, and C. Tuniz. 2015. MicroCT Imaging of Red fox Talus: A NonInvasive Approach to Evaluate Age at dDeath. Archaeometry 57(Suppl. 1):194-211. Doi: 10.1111/ arcm.12122.

Bradfield, J. 2013. Investigating the Potential of Micro -Focus Computed Tomography in the Study of Ancient Bone Tool Function: Results from aActualistic Experiments. Journal of Archaeological Science 40:2606-2613. Doi:10.1016/ j.jas.2013.02.007.

Brickley, M. and P. G. T. Howell. 1999. Measurement of Changes in Trabecular Bone Structure with Age in an Archaeological Population. Journal of Archaeological Science 26: 151-157. Doi:10.1006/ jasc.1998.0313.
Cain, C. R. 2005. Using Burned Animal Bone to Look at Middle Stone Age Occupation and Behavior. Journal of Archaeological Science 32:873-884. Doi: 10.1016/j.jas.2005.01.005.

Clark J., L. and B., Liguois. 2010. Burned Bone in the Howieson's Poort and Post-Howieson's Poort Middle Stone Age Deposits at Sibudu (South Africa): Behavioral and Taphonomic Implications. Journal of Archaeological Science 37:2650-2661. Doi: 10.1016/j.jas.2010.06.001.

Coleman, M. N. and M. W. Colbert. 2007. Technical Note: CT Thresholding Protocols for Taking Measurements on Three-Dimensional Models. American Journal of Physical Anthropology 133:723-725. Doi:10.1002/ajpa.20583.

Doube, M., M. M. Kłosowski, I. Arganda-Carreras, F. Cordelières, R. P. Dougherty, J. Jackson, B. Schmid, J. R. Hutchinson, and S. J. Shefelbine. 2010. BoneJ: Free and Extensible Bone Image Analysis in ImageJ. Bone. 47:1076-1079. Doi:10.1016/

j.bone.2010.08.023.

Hanson, M. and C. R., Cain. 2007. Examining Histology to Identify Burned Bone. Journal of Archaeological Science 34:1902-1913. Doi: 10.1016/ j.jas.2007.01.009.

Hildebrand, T. and P. Rüegsegger. 1997. Quantification of Bone Microarchitecture with the Structure Model Index. Computer Methods in Biomechanics and Biomedical Engineering 1:15-23.

Doi:10.1080/01495739708936692.

Lazenby, R. A., M. M. Skinner, T. L. Kivell, and J.-J. Hublin. 2011. Scaling VOI Size in 3D $\mu$ CT Studies of Trabecular Bone: A Test of the Over-Sampling Hypothesis. American Journal of Physical Anthropology 144:196-203. Doi:10.1002/ajpa.21385.

Macho, G. A., R. L. Abel, and H. Schutkowski. 2005. Age Changes in Bone Microstructure: Do they Occur Uniformly? International Journal of Osteoarchaeology 15:421-430. Doi:10.1002/oa.797.

McCutcheon, P. T. 1992. Burned Archaeological Bone. In Deciphering a Shell Midden, edited by J. K. Stein, pp. 347-370. Academic Press, San Diego.

Nicholson, R. A. 1993. A Morphological Investigation of Burnt Animal Bone and an Evaluation of its Utility in Archaeology. Journal of Archaeological Science 20:411-428. 
Riedel A. and U. Tecchiati. 2005. La Fauna del Luogo di Culto dell'Età del Rame di Vadena-Pfatten, Località Pigloner Kopf (Bolzano). Risultati Degli Scavi del 1998. In Atti $3^{\circ}$ Convegno Narionale di Archeozoologia (Siracusa, 2000), edited by I. Fiore, G. Malerba, and S. Chilardi, pp. 223-239. Istituto Poligrafico e Zecca dello Stato, Roma.

Shackelford, L., F. Marshall, and J. Peters. 2013. Identifying Donkey Domestication through Changes in Cross-Sectional Geometry of Long Bones. Journal of Archaeological Science 40:4170-4179. Doi:10.1016/j.jas.2013.06.006.

Shipman P., G. Foster, and M. Shoeninger. 1984. Burnt Bones and Teeth: an Experimental Study of Color, Morphology, Crystal Structure and Shrinkage. Journal of Archaeological Science 11:307-325.

Stiner M. C., S. L. Kuhn, S. Weiner, and O. BarYosef. 1995. Differential Burning, Recrystallization, and Fragmentation of Archaeological Bone. Journal of Archaeological Science 22: 223-237.

Steffen M., and Q., Mackie. 2005. An Experimental Approach to Understanding Burnt Fish Bone Assemblages within Archaeological Hearth Contexts. Canadian Zooarchaeology 23:11-38.

Tanck, E., J. Homminga, G. H. van Lenthe, and R. Huiskes. 2001. Increase in Bone Volume Fraction Precedes Architectural Adaptation in Growing Bone. Bone 28:650-654. Doi:10.1016/S8756-3282 (01)00464-1.

Thompson, T. J. U. 2004. Recent Advances in the Study of Burned Bone and their Implications for Forensic Anthropology. Forensic Science International 146:203-205. Doi:10.1016/j.forsciint.2004.09.063.

Thompson, T. J. U. and Chudek J. A. 2007. A Novel Approach to the Visualisation of Heat-Induced Structural Change in Bone. Science and Justice 47:99104. Doi:10.1016/j.scijus.2006.05.002.
Tuniz, C., F. Bernardini, A. Cicuttin, M. L. Crespo, D. Dreossi, A. Gianoncelli, L. Mancini, A. Mendoza Cuevas, N. Sodini, G. Tromba, F. Zanini, and C. Zanolli. 2013. The ICTP-Elettra X-ray Laboratory for Cultural Heritage and Archaeology. Nuclear Instruments and Methods in Physics Research Section A: Accelerators, Spectrometers, Detectors and Associated Equipment 711:106-110. Doi:10.1016/ j.nima.2013.01.046.

Tuniz, C., F. Bernardini, I. Turk, L. Dimkaroski, L. Mancini, and D. Dreossi. 2012. Did Neanderthals Play Music? X-Ray Computed Micro-Tomography of the Divje Babe 'Flute'. Archaeometry 54:581-590. Doi: 10.1111/j.1475-4754.2011.00630.x.

von den Driesch, A. 1976. A Guide to the Measurements of Animal Bones from Archaeological Sites. Peabody Museum Bulletins 1, Peabody Museum of Archaeology and Ethnology, Harvard University, Cambridge, MA.

Whyte, T. R. 2001. Distinguishing Remains of Human Cremations from Burned Animal Bones. Journal of Field Archaeology 28:437-448.

\section{Biosketches}

Francesco Boschin is collaborating with the University of Siena (Italy) carrying out zooarchaeological research and taphonomic studies on Pleistocene and Holocene faunal assemblages in Italy. In the last years he developed new applications of 3D microscopy and MicroCT imaging on faunal remains.

Clément Zanolli is carrying out several palaeoanthropological studies focusing his interest in the application of MicroCT imaging in the analysis of primate skeletal remains.

Claudio Tuniz is scientific consultant of the ICTP (the "Abdus Salam" International Centre for Theoretical Physics of Trieste, Italy) and the coordinator of the X-ray Microanalysis for Archaeology and Palaeoanthropology Project, at the ICTP Multidisciplinary Laboratory. 